\title{
Bibliometric Studies on Multi-Criteria Decision Analysis (MCDA) Applied in Personnel Selection
}

\author{
Igor Pinheiro de Araújo COSTA ${ }^{\mathrm{a}, \mathrm{d}, 1}$, Marcio Pereira BASÍLIO ${ }^{\mathrm{b}}$, Sérgio Mitihiro do \\ Nascimento MAÊDA ${ }^{\mathrm{a}, \mathrm{d}}$, Marcus Vinícius Gonçalves RODRIGUES ${ }^{\mathrm{a}}$, Miguel Ângelo \\ Lellis MOREIRA ${ }^{\mathrm{a}, \mathrm{d}}$, Carlos Francisco Simões GOMES ${ }^{\mathrm{a}}$ and Marcos dos SANTOS ${ }^{\mathrm{c}, \mathrm{d}}$ \\ ${ }^{a}$ Federal Fluminense University, Brazil \\ ${ }^{b}$ Military Police of the State of Rio de Janeiro, Brazil \\ ${ }^{c}$ Military Institute of Engineering, Brazil \\ ${ }^{d}$ Naval Systems Analysis Center, Brazil
}

\begin{abstract}
Personnel selection is increasingly proving to be an essential factor for the success of organizations. These issues almost universally involve multiple conflicting objectives, uncertainties, costs and benefits in the decision-making process. In this context, due to the characteristics of human resources problems, composed of several subjective evaluation criteria, such problems can be solved by applying Multiple Criteria Decision Aid (MCDA) methods. This paper aims to present a literature review on the main applications of MCDA in the personnel selection area, considering the tactical, operational and strategic spheres. The methodology includes a bibliometric study and a literature review of documents from the Scopus database. We identified the document type, year of publication, affiliation, authors, author's H-index, the field of knowledge, country and keyword clusters. The literature review allowed us to verify that the Fuzzy Logic is the most applied methodology in personnel selection problems with MCDA, due to its capacity to handle vague, imprecise and subjective data.
\end{abstract}

Keywords. Multi-criteria Decision Analysis (MCDA), Bibliometric Studies, Personnel Selection, Fuzzy Logic.

\section{Introduction}

Personnel selection is one of the problems that organizations are increasingly facing, as people represent one of the most important resources in companies [1]. According to [2], this selection is a significant task, as it aims to select the best candidates to perform the business functions.

In this sense, Multi-criteria Decision Aid (MCDA) describes methods that address multiple criteria to help individuals and groups make important decisions. [3]. MCDA is composed of a set of alternatives, at least two criteria and at least one Decision Maker (DM) [4].

${ }^{1}$ Corresponding Author, Igor Pinheiro de Araújo COSTA, Department of Production Engineering, Federal Fluminense University, Niterói, Brazil; E-mail: costa_igor@id.uff.br.

This research was financially supported by Naval Systems Analysis Center (CASNAV), Brazil. 
The academic literature presents several applications of MCDA methods in personnel selection, in the tactical, operational and strategic spheres. However, there is a lack of studies on publishing trends in this important area for business and human resources management. Therefore, this research aims to fill this gap, presenting a literature review on the main applications of MCDA in the personnel selection problems.

Following the methodology presented by [5], we analyzed MCDA applications in personnel selection, to explore: the main authors, countries, journals and knowledge areas that publish papers on the subject; the number of works published; and the main keywords used in the papers.

This paper presents the results of bibliographic research on MCDA and personnel selection, providing a descriptive overview of the scientific production of both themes. A bibliometric study was performed on the Scopus database to achieve this goal.

\section{Background}

In the personnel selection process, several attributes are usually evaluated such as analytical ability, innovation, leadership and personality. Therefore, Human Resources Management (HRM) plays a significant role in business administration [5].

For $[5,6]$ personnel selection problems involve multiple candidates as alternatives, together with many complex criteria, which can be solved by MCDA methods. The multicriteria methods have been applied to support the decision-making process in recent complex problems, such as [7-13].

Nabeeh et al. [14] claim that the complexity of this type of problem is to establish the appropriate application to meet the company's requirements, which makes the process excessively subjective and complex. The environment of decision-making is surrounded by inconsistency and uncertainty [14].

For [13], without a proper and accurate method for HR problems, the performance of the project will be affected, and the MCDA is suggested to be a viable method for this kind of problem.

Among the main applications of MCDA in personnel selection, we highlight: a hybrid MCDA model for sniper selection [16]; competency frameworks for choosing the best information technology (IT) expert [6,16]; selection of a chief accounting officer, managing information assessed using both linguistic and numerical scales [17]; selection of best employees to a supply chain firm [18]; selection from security personnel [19]; selection of a candidate for the position of the sales manager [20].

The literature presents several applications combining MCDA methods to support the decision-making process in personnel selection problems, in most cases applying a method to obtain the weights of the criteria and another one to evaluate the alternatives, taking advantage of each method's characteristics.

Also, we observed that the fuzzy logic is routinely applied in personnel selection problems with MCDA. Given the great subjectivity and uncertainties related to personnel selection, it is justified by the fact that the fuzzy approaches handle vagueness and imprecision better [21]. These findings corroborate the impressions of several authors, such as [22] and [23], who applied fuzzy logic in conjunction with multicriteria methods to deal with data characterized by inconsistency and uncertainty in multicriteria problems. 


\section{Methodology}

This study considered the Webibliomining model [24], chosen for integrating concepts from Bibliometrics, Webmetrics, Informetrics and Bibliomining. In this section, an adaptation of the model proposed by [24-26] was applied. The following strategy was tested in the Scopus database to find documents on applications of MCDA methods in personnel selection problems, linking both research themes:

- TITLE-ABS-KEY ((MCDA OR MCDM) AND (PERSONNEL SELECTION)).

The research was carried out in the Scopus database in May 2021 (Table 1). There were no limits of date, document type, or access type. In all, 63 studies were found with the themes analyzed.

Table 1. Search results in the SCOPUS database.

\begin{tabular}{lll}
\hline Document type & Number of articles & \% \\
\hline Journal article & 52 & $82.5 \%$ \\
Conference paper & 9 & $14.3 \%$ \\
Book Chapter & 2 & $3.2 \%$ \\
Total & 63 & $100,0 \%$ \\
\hline
\end{tabular}

A bibliometric study was developed to identify the year of publication, journals, clusters of keywords, authors (including the authors' H-index), affiliation, country/territory and fields of knowledge. VOSviewer software was used to analyze keyword clusters. It is a tool for creating maps, viewing and exploring [27]. According to [28], increasing publication rates and fragmented research streams make the use of bibliometric essential for scientific mapping.

\section{Results and analysis}

The first paper was published in 1994. From 1995 to 2003 and 2006 to 2009 there were no published articles. From 2010 to 2020, there was a significant increase in the number of articles published with fluctuations from 2 to 11 articles per year. In 2018, there was the highest number of publications (11 articles).

Table 2 shows the distribution of articles by journal, considering 2 or more works. The journals Expert Systems With Applications and Life Science presented the highest number of articles published in the area of personnel selection with MCDA applications (4 papers). There are also 9 journals with 2 articles each, and 26 journals with 1 published article, totaling 37 . Therefore, it is noted that the articles are distributed by a wide variety of journals.

Table 2. Distribution of articles by journal.

\begin{tabular}{ll}
\hline Journal & Number of articles \\
\hline Expert Systems With Applications & 4 \\
Life Science Journal & 4 \\
European Journal Of Operational Research & 2 \\
Applied Soft Computing Journal & 2 \\
Economic Computation And Economic Cybernetics Studies And Research & 2 \\
Human Factors And Ergonomics In Manufacturing & 2 \\
Informatica (Netherlands) & 2 \\
Journal Of Enterprise Information Management & 2 \\
Journal Of Multiple Valued Logic And Soft Computing & 2 \\
Scientific World Journal & 2 \\
Soft Computing & 2 \\
\hline
\end{tabular}


Analyzing the words can bring information and knowledge about a certain subject [29]. This research used VOSviewer software to analyze keywords, including author and index keywords. The keyword "personnel selection" has the highest number of occurrences, followed by "decision making". The terms most related to personnel problems are "risk assessment", "human resources" and "enterprise resource management". Among the MCDA methods, the Analytic Hierarchy Process (AHP), Technique for Order Preferences by Similarity To Ideal Solution (TOPSIS), Additive Ratio Assessment (ARAS) and Elimination Et Choix Traduisant la Realité (ELECTRE) stand out in the analysis of keywords.

The first applications dealt with HR management, while the most recent ones seem to indicate a trend of research more focused on risk assessment, with qualitative approaches involving linguistic variables and fuzzy logic. Table 3 shows the distribution of articles per author, in descending order according to the number of published papers and H-Index, considering 3 or more published articles. The $\mathrm{H}$-index is defined as the number of articles with citation numbers greater than or equal to $\mathrm{H}$, as a useful index to characterize the scientific production of a researcher [30]. There are 2 authors with 6 articles: Stanujkic, D. $(\mathrm{H}=19)$ and Karabasevic, D. $(\mathrm{H}=13) .2$ authors published 5 articles each, with emphasis on the author Zavadskas, E.K., who has an Hindex $=77$. Besides, there is an author with 4 articles, 3 authors with 3 papers, 14 researchers with 2 articles and 116 authors with one article each, totaling 138 authors.

Table 3. Distribution of articles by author.

\begin{tabular}{lll}
\hline Author & Articles & H-Index \\
\hline Stanujkic, D. & 6 & 19 \\
Karabasevic, D. & 6 & 13 \\
Zavadskas, E.K. & 5 & 77 \\
Turskis, Z. & 5 & 54 \\
El-Santawy, M.F. & 4 & 4 \\
Aliguliyev, R. & 3 & 20 \\
Ahmed, A.N. & 3 & 4 \\
Yusifov, F. & 3 & 2 \\
\hline
\end{tabular}

Table 4 shows the institutions that have published 2 or more papers. The institution Vilniaus Gedimino Technikos Universitetas stands out with 11 documents, followed by the University of Belgrade, with 5 articles. Also, there are 2 institutions with 3 and 4 articles each, 5 universities with 2 papers and 72 institutions with 1 article each, totaling 83.

Table 4. Distribution of articles by institution.

\begin{tabular}{ll}
\hline Institution & Articles \\
\hline Vilniaus Gedimino Technikos Universitetas & 11 \\
University of Belgrade & 5 \\
Cairo University & 4 \\
Azerbaijan National Academy of Sciences & 4 \\
University Business Academy in Novi Sad & 3 \\
Galatasaray Universitesi & 3 \\
Zagazig University & 2 \\
University of Tehran & 2 \\
The University of New Mexico - Gallup & 2 \\
Ming Chuan University & 2 \\
Mykolas Romeris University & 2 \\
\hline
\end{tabular}

Table 5 shows the distribution of articles by country or territory. The search found 21 countries. Lithuania ranks first with 12 articles, followed by Turkey with 11 
documents. Asia, with 9 countries, has 39 articles (62\% of the total). Europe is represented by 8 countries with 28 articles published (44\% of the total). Africa, represented by 2 countries, has 7 published articles (11\%). The American continent, with 1 country, has 3 articles (5\% of the total). Oceania, through New Zealand, has 1 article ( $2 \%$ of the total).

Table 5. Distribution of articles by country or territory.

\begin{tabular}{ll}
\hline Country/territory & Articles \\
\hline Lithuania & 12 \\
Turkey & 11 \\
Taiwan & 9 \\
Egypt & 6 \\
India & 6 \\
Serbia & 6 \\
Azerbaijan & 5 \\
Iran & 4 \\
China & 3 \\
United States & 3 \\
Vietnam & 3 \\
\hline
\end{tabular}

Table 6 shows the distribution of articles by field of knowledge: Computer science (28.7\%), Engineering (14.7\%), Mathematics (12.4\%), Business Management $(9.3 \%)$ and Decision Sciences $(8.5 \%)$ stand out compared to other areas, with approximately $74 \%$ of the total articles.

Table 6. Distribution of articles by area of knowledge.

\begin{tabular}{ll}
\hline Subject area & Articles (\%) \\
\hline Computer Science & $37(28.7 \%)$ \\
Engineering & $19(14.7 \%)$ \\
Mathematics & $16(12.4 \%)$ \\
Business, Management and Accounting & $12(9.3 \%)$ \\
Decision Sciences & $11(8.5 \%)$ \\
Economics, Econometrics and Finance & $7(5.4 \%)$ \\
Biochemistry, Genetics and Molecular Biology & $6(4.7 \%)$ \\
Social Sciences & $6(4.7 \%)$ \\
\hline
\end{tabular}

\section{Conclusions}

The bibliometric study provided a descriptive overview of scientific production on applications of MCDA methods in personnel selection problems. The literature review, although not exhaustive, showed several concepts, paradigms, steps and applications in different personnel problems. The papers are divided by several journals, and there is not one that can be pointed out as the greatest reference in personnel selection with MCDA.

Regarding the authors, no one can be considered as the largest reference in the area. The distribution by field of knowledge showed that the articles are spread over several areas, illustrating the multidisciplinarity of the themes under study.

The analysis of the keywords allowed us to verify that, among the MCDA methods, four of them stand out: AHP, TOPSIS, ARAS and ELECTRE. Also, through the temporal analysis of keywords, we verified that the most recent applications seem to indicate a trend of research more focused on risk assessment, with qualitative approaches involving linguistic variables and fuzzy logic. This trend is probably 
justified by the capacity to deal with imprecise, vague, and subjective data that Fuzzy Logic offers the DM.

Because of the above, this research fulfilled the gap in the literature, presenting the state of the art of applications in MCDA methods in a field that is so important for the success of companies - personnel selection. As future work, we suggest more detailed studies on the competencies considered most important in the process of choosing employees in the most diverse fields of human activity.

\section{References}

[1]. Ulutaş A, Popovic G, Stanujkic D, Karabasevic D, Zavadskas EK, Turskis Z. A new hybrid mcdm model for personnel selection based on a novel grey piprecia and grey OCRA methods. Mathematics [Internet]. 2020;8(10):1-14. Available from: https://www.scopus.com/inward/record.uri?eid=2-s2.0$85092918383 \&$ doi $=10.3390 \% 2$ Fmath8101698\&partnerID=40\&md5=fd6228a310ade407ef6f60dffd9efc $0 \mathrm{c}$

[2]. Abdel-Basset M, Gamal A, Son LH, Smarandache F. A bipolar neutrosophic multi criteria decision making framework for professional selection. Appl Sci [Internet]. 2020;10(4). Available from: https://www.scopus.com/inward/record.uri?eid=2-s2.0-

$85081200450 \&$ doi $=10.3390 \% 2 F a p p 10041202 \&$ partnerID=40\&md5=18047ba29b237adf782c23417b73 $\mathrm{db} 70$

[3]. Belton V, Stewart T. Multiple criteria decision analysis: an integrated approach. Springer Science \& Business Media; 2002.

[4]. Greco S, Figueira J, Ehrgott M. Multiple Criteria Decision Analysis: State of art surveys. Vol. 37. Springer; 2016.

[5]. Ijadi Maghsoodi A, Riahi D, Herrera-Viedma E, Zavadskas EK. An integrated parallel big data decision support tool using the W-CLUS-MCDA: A multi-scenario personnel assessment. KnowledgeBased Syst [Internet]. 2020;195. Available from: https://www.scopus.com/inward/record.uri?eid=2s2.0-

85082191498\&doi $=10.1016 \% 2$ Fj.knosys.2020.105749\&partnerID $=40 \& m d 5=0080$ ce509da $1 \mathrm{f} 9 \mathrm{~b} 4 \mathrm{e} 6 \mathrm{adb}$ 528954 fad7a

[6]. Raj Mishra A, Sisodia G, Raj Pardasani K, Sharma K. Multi-criteria it personnel selection on intuitionistic fuzzy information measures and aras methodology. Iran J Fuzzy Syst [Internet]. 2020;17(4):55-68. Available from: https://www.scopus.com/inward/record.uri?eid=2-s2.0$85085562628 \&$ doi $=10.22111 \% 2$ Fijfs.2020.5406\&partnerID $=40 \&$ md5=b85b97852e9c2fc10c8d83fe59 298565

[7]. Costa IP de A, Sanseverino AM, Barcelos MR dos S, Belderrain MCN, Gomes CFS, Santos M dos. Choosing flying hospitals in the fight against the COVID-19 pandemic: structuring and modeling a complex problem using the VFT and ELECTRE-MOr methods. IEEE Lat Am Trans. 2021;19(6):1099_ 106.

[8]. Moreira MÂL, Costa IP de A, Pereira MT, dos Santos M, Gomes CFS, Muradas FM. PROMETHEESAPEVO-M1 a Hybrid Approach Based on Ordinal and Cardinal Inputs: Multi-Criteria Evaluation of Helicopters to Support Brazilian Navy Operations. Algorithms [Internet]. 2021 Apr 27;14(5):140. Available from: https://www.mdpi.com/1999-4893/14/5/140

[9]. Oliveira AS, Gomes CFS, Clarkson CT, Sanseverino AM, Barcelos MRS, Costa IPA, et al. Multiple Criteria Decision Making and Prospective Scenarios Model for Selection of Companies to Be Incubated. Algorithms [Internet]. 2021 Mar 30;14(111). Available from: https://www.mdpi.com/19994893/14/4/111

[10]. Maêda; SM do N, Costa IP de A, Castro Junior MAP, Fávero LP, Costa AP de A, Corriça JV de P, et al. Multi-criteria analysis applied to aircraft selection by Brazilian Navy. Production. 2021;31:1-13.

[11]. Santos M dos;, Costa IP de A, Gomes CFS. Multicriteria decision-making in the selection of warships: a new approach to the AHP method. Int J Anal Hierarchy Process [Internet]. 2021 May 19;13(1). Available from: https://ijahp.org/index.php/IJAHP/article/view/833

[12]. de Almeida IDP, Corriça JV de P, Costa AP de A, Costa IP de A, Maêda SM do N, Gomes CFS, et al. Study of the Location of a Second Fleet for the Brazilian Navy: Structuring and Mathematical Modeling Using SAPEVO-M and VIKOR Methods. ICPR-Americas 2020 Commun Comput Inf Sci [Internet]. 2021;1408:113-24. Available from: https://link.springer.com/10.1007/978-3-030-76310-7_9 
[13]. Costa IP de A, Maêda SM do N, Teixeira LFH de S de B, Gomes CFS, Santos M dos. Choosing a hospital assistance ship to fight the Covid-19 pandemic. Rev Saude Publica [Internet]. 2020;54. Available from: $85090141296 \&$ doi $=10.11606 \% 2 F S 1518$ 8787.2020054002792\&partnerID=40\&md5=90355a4a86a1b09b1add8956ace 15019

[14]. Nabeeh NA, Smarandache F, Abdel-Basset M, El-Ghareeb HA, Aboelfetouh A. An Integrated Neutrosophic-TOPSIS Approach and Its Application to Personnel Selection: A New Trend in Brain Processing and Analysis. IEEE Access [Internet]. 2019;7:29734-44. Available from: https://www.scopus.com/inward/record.uri?eid=2-s2.0-

85064717679\&doi=10.1109\%2FACCESS.2019.2899841\&partnerID=40\&md5=c8d63c0f9059bb4f005 c3fcfe5841ef9

[15]. Cheng EWL, Li H. Contractor selection using the analytic network process. Constr Manag Econ [Internet]. 2004;22(10):1021-32. Available from: https://www.scopus.com/inward/record.uri?eid=2s2.0-

$11944249373 \&$ doi $=10.1080 \% 2 F 0144619042000202852 \&$ partnerID $=40 \& \mathrm{md} 5=$ fac 75 ca 73 bea $9 \mathrm{~d} 715012$ $6682 \mathrm{cf} 3 \mathrm{eac} 5 \mathrm{~d}$

[16]. Kabak M, Burmaoğlu S, Kazançoğlu Y. A fuzzy hybrid MCDM approach for professional selection. Expert Syst Appl [Internet]. 2012;39(3):3516-25. Available from: https://www.scopus.com/inward/record.uri?eid=2-s2.0-

80255127315\&doi=10.1016\%2Fj.eswa.2011.09.042\&partnerID=40\&md5=19e4bb9448212f89daf636c $6 \mathrm{c} 5 \mathrm{f} 2602 \mathrm{~d}$

[17]. Keršuliene V, Turskis Z. A hybrid linguistic fuzzy multiple criteria group selection of a chief accounting officer. J Bus Econ Manag [Internet]. 2014;15(2):232-52. Available from: https://www.scopus.com/inward/record.uri?eid=2-s2.0-

84899869374\&doi=10.3846\%2F16111699.2014.903201\&partnerID $=40 \& \mathrm{md} 5=\mathrm{fc} 7 \mathrm{dd} 4831783 \mathrm{fee} 4077 \mathrm{e}$ $\mathrm{a} 06 \mathrm{db} 0 \mathrm{fc} 7602$

[18]. Dwivedi P, Chaturvedi V, Vashist JK. Efficient team formation from pool of talent: comparing AHPLP and TOPSIS-LP approach. J Enterp Inf Manag [Internet]. 2020;33(5):1293-318. Available from: https://www.scopus.com/inward/record.uri?eid=2-s2.0-85084979643\&doi=10.1108\%2FJEIM-092019-0283\&partnerID=40\&md5=c9ca04552dd3888fcd77bb4e80b6c182

[19]. Krylovas A, Zavadskas EK, Kosareva N, Dadelo S. New KEMIRA method for determining criteria priority and weights in solving MCDM problem. Int $J$ Inf Technol Decis Mak [Internet]. 2014;13(6):1119-33. Available from: https://www.scopus.com/inward/record.uri?eid=2-s2.084929300521\&doi=10.1142\%2FS0219622014500825\&partnerID=40\&md5=61a8e591d6f9b1eb58067 da73b64a5a9

[20]. Karabasevic D, Zavadskas EK, Turskis Z, Stanujkic D. The Framework for the Selection of Personnel Based on the SWARA and ARAS Methods Under Uncertainties. Inform [Internet]. 2016;27(1):49-65.

[21]. Krishankumar R, Premaladha J, Ravichandran KS, Sekar KR, Manikandan R, Gao XZ. A novel extension to VIKOR method under intuitionistic fuzzy context for solving personnel selection problem. Soft Comput [Internet]. 2020;24(2):1063-81. Available from: https://www.scopus.com/inward/record.uri?eid=2-s2.0-85064160864\&doi=10.1007\%2Fs00500-01903943-2\&partnerID=40\&md5=1406f69b9844add7b5578e50d4382267

[22]. Baležentis T, Zeng S. Group multi-criteria decision making based upon interval-valued fuzzy numbers: An extension of the MULTIMOORA method. Expert Syst Appl [Internet]. 2013;40(2):543-50.

[23]. Kilic HS, Demirci AE, Delen D. An integrated decision analysis methodology based on IF-DEMATEL and IF-ELECTRE for personnel selection. Decis Support Syst [Internet]. 2020;137.

[24]. Costa HG. Model for webibliomining: proposal and application. Rev FAE. 2010;115-26.

[25]. De Barros MD, Salles CAL, Gomes CFS, Da Silva RA, Costa HG. Mapping of the scientific production on the ITIL application published in the national and international literature. In: R. C, Y. S, P. W, E. H-V, L.F.A.M. G, Y. S, editors. Universidade Federal Fluminense, 156 - Sao Domingos Rua Passos da Patria, Niteroí - RJ, 24210-240, Brazil: Elsevier B.V.; 2015. p. 102-11.

[26]. Da Silva GB, Costa HG, De Barros MD. Entrepreneurship in engineering education: A literature review. Int J Eng Educ. 2015;31(6):1701-10.

[27]. Van Eck NJ, Waltman L. Manual for VOSviewer version 1.6. 8. CWTS Meaningful Metrics Univ Leiden. 2018;

[28]. Aria M, Cuccurullo C. bibliometrix: An R-tool for comprehensive science mapping analysis. J Informetr. 2017;11(4):959-75.

[29]. Ishikiriyama CS, Miro D, Gomes CFS. Text Mining Business Intelligence: a small sample of what words can say. Procedia Comput Sci. 2015;55:261-7.

[30]. Hirsch JE. An index to quantify an individual's scientific research output. Proc Natl Acad Sci. 2005;102(46):16569-72. 